\title{
THE MEDIATING ROLE OF PERSON- ORGANIZATION FIT IN THE SUPPORTIVE LEADERSHIP-OUTCOME RELATIONSHIPS
}

Alptekin Sökmen, M. Gökhan Bitmiş, M. Mithat Üner

\section{Introduction}

Leadership has been studied in a variety of fields from management, psychology, education to military due to the its increasing importance in today's business environments. The changing nature of today's employment conditions and psychological contracts demands employees to increase consistently their skills and abilities. Therefore, organizations should pay attention to give opportunities and provide resources to employees in order to develop their employability in exchange for increased level of productivity and commitment [45], [35]. Therefore, leader or manager's behavior will have positive motivational effect in this process. One sub dimension of the House and Mitchell [20] model of leader behaviors, supportive leader behavior has been defined as the behavior directed toward the satisfaction of employees' needs and preferences by creating friendly and psychologically supportive work environment and also showing interest for subordinate's welfare [20]. By exerting supportive leader behavior, leaders may help their employees succeed in today's work environment, especially in which tasks are interdependent, ambiguous, varied, and stress inducing (e.g. telecommunication industry). Research shows that supportive leadership has positive effects and enjoyment in the workplace by providing socio-emotional support. Thus, it is linked to job outcomes such as job satisfaction [23], [35] and turnover intentions [14]. Researchers and practitioners also claim that another important factor to succeed in a competitive business environment by maintaining flexible and committed workforce is person-organization fit (P-O fit) [25]. P-O fit has important implications for a variety of workplace outcomes such as job satisfaction, turnover, and commitment [44]. The distinguishing feature of this study is that although the effect of supportive leadership behavior on job satisfaction and turnover intentions has been documented in the literature, the effect of $\mathrm{P}-\mathrm{O}$ fit in these relationships has not sufficiently examined. As shown in our theoretical model (see Fig.1), we suggest that $\mathrm{P}-\mathrm{O}$ fit will serve as an explanatory variable between supportive leadership and job outcomes. Therefore, the purpose of this study is to propose and test a mediation model, in which supportive leader behavior affects job satisfaction and turnover intentions via perceptions of person-organization fit.

\section{Literature Review}

\subsection{Supportive Leadership, Person-Organization Fit, Job Satisfaction, and Turnover Intentions Relationships}

Supportive leader behavior, which is rooted from path-goal theory of leader effectiveness, [19], [20] is one of the critical variables in order to motivate employees in work settings. It is a leadership behavior towards the satisfaction of employees' needs and preferences by creating a friendly and psychologically supportive work environment. In general, supportive leader behavior provides psychological support for subordinates [22]. According to social exchange theory, employee behavior is influenced by the supportiveness of the leaders [7]. Supportive relationships increase the quality of relationships between superiors and subordinates [18], which in turn, have an impact on job satisfaction, and turnover intentions [17]. Supportive leader behavior was also asserted to be a source of self confidence, stress reduction, and alleviation of frustration [20].

On the other hand, P-O fit can be defined as an employee's perceived compatibility or comfort with an organization [30]. This is called direct or perceived P-O fit measurement 
since respondents themselves estimate the extent their values are similar to those of the organization [16]. Some researchers have been used indirect measurement or calculated fit, in which individual and organizational values are assessed on the same content dimensions, when measuring $\mathrm{P}-\mathrm{O}$ fit. However, Tepeci [42] shows that perceived fit was the superior predictor and explained more outcome variance, when comparing perceived fit with calculated fit. Therefore, we used perceived fit in this study.

$\mathrm{P}-\mathrm{O}$ fit occurs when an organization satisfies individuals' needs, desires or preferences in terms of need-supplies perspective [25]. Therefore, leaders can increase $\mathrm{P}-\mathrm{O}$ fit by displaying supportive leader behavior that is showing close interest to employees' welfare and creating friendly and psychologically supportive work environments. Thus, we expect that subordinates will be much fit to organization when they perceive their immediate supervisors or managers as being supportive of them and their work. Therefore, the first hypothesis will be as follows:

$\mathrm{H}_{1}$ : Supportive Leadership is positively related to organizational fit.

Turnover intent is a warning sign before an employee actually quits a job [24]. It is defined as the reflection of the subjective probability that an employee will change his or her job within a certain time period [40]. Turnover intentions show the intent of an employee to abandon his or her organizational membership and quit his or her current job [29]. It is a predictor of actual turnover; specifically actual turnover is expected to increase as the intention increases. Moreover, it is related to job satisfaction, which is defined as individual's global feelings about their job [41]. Positive job satisfaction is thought to decrease one's intent to turnover [43]. Using the Schneider's [37] Attraction-SelectionAttrition (ASA) model as a theoretical lens, we can understand that individuals are not randomly assigned to situations, but rather they seek out situations that are attractive to them. Schneider [37] claims that organizations are one situation that employees are attracted to, selected to be a part of and remain with, if they are a good fit with the organization, or leave, if they are not a good fit with the organization. O'Reilly, Chatman, and Caldwell [31] found that employees whose individual values did not match with the organization's values (low person-organization fit) were more likely to have high levels of turnover intentions. Also, a number of studies show that higher $\mathrm{P}-\mathrm{O}$ fit leads to lower turnover intentions [26], [44]. When employees do not fit their environment, they will probably experience feelings of incompetence, demoralization, and anxiety. On the other hand, when their perceived fit to the organization becomes higher, they will experience more positive effect, which will result with increased satisfaction and such employees are also likely to choose to stay in that organization [32], [15], [11]. Chatman [11] found that person-organization fit is positively associated with satisfaction and negatively

\section{Fig. 1: Hypothesized model}

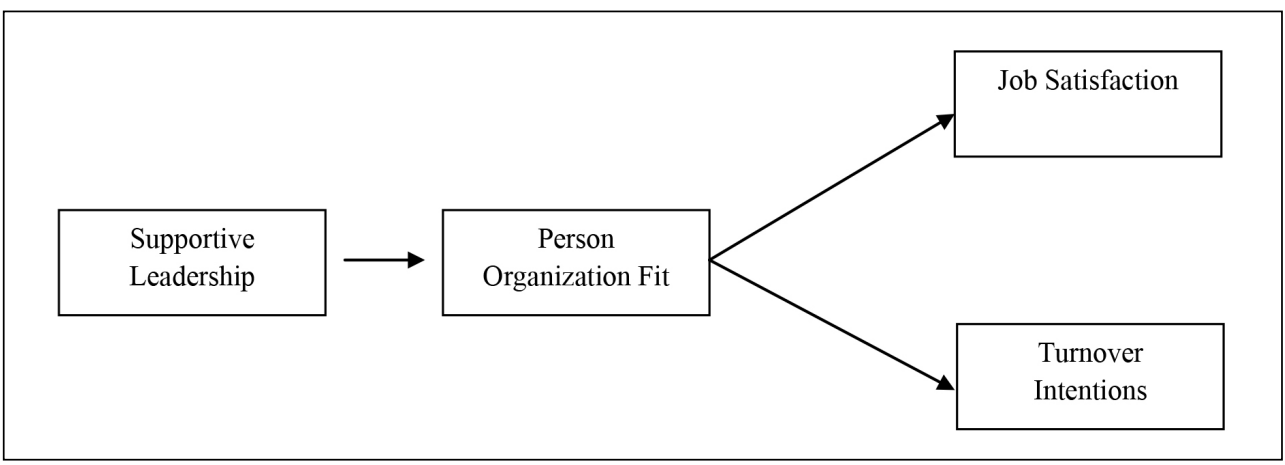


associated with intent to leave in a study of U.S. public accounting firms. Schneider, Goldstein, and Smith [38] argue that fit yields satisfaction and commitment, which in turn these will cause retention and those, who do not fit will leave. Downey, Hellriegel, Slocum [13] claim that individuals requiring social contact and interdependence with others were more satisfied in organizations with open and empathic climates than those with closed, bureaucratic, and impersonal ones. Further; Saks, Uggerslev \& Fassina [36] reveal that $\mathrm{P}-\mathrm{O}$ fit partially mediates the relationship between socialization tactics and some distal outcomes such as job satisfaction and turnover intentions. Therefore, we expect that when managers provide support for their employees, this will probably increase employees' self confidence and decrease the stress level of them. Thus, they will probably perceive that they fit better to organization, which in turn result with increased level of job satisfaction and decreased level of turnover intentions. Therefore, P-O fit provides an explanatory mechanism through which supportive leadership is related to the work related consequences. Given these arguments, the following hypotheses were proposed:

$\mathrm{H}_{2}$ : Organizational fit is (a) positively related to job satisfaction, and negatively related to (b) turnover intentions.

$\mathrm{H}_{3}$ : Organizational fit mediates the relationships between supportive leadership and (a) job satisfaction, (b) turnover intentions.

\section{Method}

\subsection{Data Collection Procedure and Sample}

Our sample consisted of employees from one of the leading group in telecommunications industry in Turkey. The company is one of the country's key communication and technology group, which provides integrated telecommunication and convergence technology services to both individual and non-individual customers. Although the company has major strengths based on profitability, brand valuation, and market position; a general drop in headcount has been observed over the past few years. Thus, we selected this group as our targeted survey sample for this study.

Our sample source truly reflects the target population. Survey questionnaires were randomly distributed to 360 specialists in the organization. The respondents were presented, either in person or via email, with the selfadministered questionnaire, which was tailored for this research in order to reach individuals, with characteristics typical of those possessed by our population of interest. We received responses from 320 (88\% response rate) fulltime employees. However, some of them were discarded due to the excessive missing data, resulting 310 useable questionnaires. Average age and tenure of the respondents were 34.37 and 9.25 years, respectively and $63 \%$ of the respondents were male.

\subsection{Measures}

The constructs in our study are developed by using measurement scales adopted from prior studies. All of the survey items, excluding demographic ones were responded to on fivepoint Likert scales, with anchors ranging from strongly disagree (1) to strongly agree (5). Some of the items were negatively worded. After reversing these, the items in each scale were averaged to create an overall variable score, which higher ones reflect greater tendency towards supportive leadership, job satisfaction, person-organization fit, and intentions of leaving the organization.

\section{Supportive leadership}

Supportive leadership is a behavior towards the satisfaction of individual's needs and preferences [22]. Ten items taken from the House and Dessler's [21] supportive leadership dimension of Perceived leadership behavior scale (PLBS) were used to measure supportive leadership behavior. This scale measures the degree to which leader behavior can be characterized as friendly, approachable, and considered of the needs and preferences of employees. The Cronbach's alpha coefficient for this scale was 0.91. A sample item included "My manager looks out for the personal welfare of group members."

\section{Job satisfaction}

Job satisfaction is defined as individual's global feelings about their job [41]. It was assessed by using 6-item Global measure of job satisfaction scale, which was originally developed by Brayfield and Rothe [9] and subsequently modified by Agho, Price and Mueller [1]. The Cronbach's alpha coefficient was 0.85 . A sample item included "I feel fairly well satisfied with my job." 


\section{Person-organization fit}

Fit refers an employee's perceived compatibility or comfort with an organization. Nine items taken from Mitchell et al. [30] fit to organization dimension of organizational job embeddedness scale made-up the fit measure. This scale measures participant's agreement in the concordance between their values, career goals, and plans for the future and those of the corporate culture and the demands of his or her current job such as job abilities, knowledge and skills [30]. The Cronbach's alpha coefficient was 0.88 . A sample item from this scale was "I feel like I am a good match for this company."

\section{Turnover intentions}

Turnover intentions are defined as the intent of an employee to abandon his or her organizational membership [29]. These intentions were measured by using Bluedorn [8] three-item scale $(\alpha=0.90)$. A sample item included "It is likely that I will actively look for a new job this year."

\section{Control variables}

We introduced three control variables to account for variance explained in alienation. These items were measured with self-reported single item questions. We controlled for age (measured in years), gender (male $=1$, female $=2$ ), tenure (measured in years) in order to eliminate spurious relationships between our variables.

\section{Translation}

Surveys were administered in Turkish. Original surveys were translated from English to Turkish using "back translation" method [10]. Two bilingual research assistants, who were blind to the nature of the study and hypotheses, completed the translation. Disagreements were resolved by consensus-based discussions between the authors, two translators, and another bilingual expert.

\section{Analyses and Results}

We followed Baron and Kenny's [4] three-step regression procedure in order to determine whether $\mathrm{P}-\mathrm{O}$ fit mediated the relationships between supportive leadership and the outcomes in this study. First, the independent variable (supportive leadership) should be significantly related to the mediator variable (P-O fit), and it is in this step that we test
Hypothesis one. Second, the independent variable (supportive leadership) should be related to the dependent variables. Third, the mediator variable ( $\mathrm{P}-\mathrm{O}$ fit) should be related to the dependent variables with the independent variable (supportive leadership) included in the equation. We test hypothesis two and three in this step. If the first three conditions hold and the effect of the independent variable (supportive leadership) on the dependent variables is less in the third equation than in the second one, the mediation is established. This is called partial mediation. Full mediation holds if the independent variable has no effect when the mediator is introduced into the model in the third step. Moreover, the Sobel test was also used in this study to measure the significance of the indirect effect of the independent variable on the dependent variables via the mediator [39]. In other words, we conducted Sobel's test in order to examine whether P-O fit carried the effects of supportive leadership significantly on to outcomes such as job satisfaction and turnover intentions.

Table 1 presents means, standard deviations, and Pearson correlations among the variables in the study. The correlations reveal that supportive leadership was significantly correlated with person-organizational fit (.47, $\mathrm{p}<.01)$, job satisfaction $(.41, p<.01)$, and turnover intentions $(-.17, \mathrm{p}<.01)$. P-O fit was also significantly correlated with job satisfaction $(.70, p<.01)$, and turnover intentions (-.29, $p<.01)$. The correlations were in the expected directions and in line with previous research (e.g. Kristof [25], Verquer et al. [44]). We also implemented a series of confirmatory factor analyses (CFAs) that included a 4-factor model and three alternative models in order to provide additional evidence for the discriminant validity of our variables. The results of our CFAs are provided in Table 2.

We used chi-square statistics and some model fit indices such as Root Mean Square Error of Approximation (RMSEA), Tucker Lewis Index (TLI), Akaike Information Criterion (AIC), and Comparative Fit Index (CFI). First, $\mathrm{X}^{2} / \mathrm{df}$ ratio is less than 3 for our hypothesized 4-factor model, which is a threshold of a minimal acceptance value suggested by Bentler and Bonett [6]. Second, CFI and TLI are two commonly used goodness-of-fit indices, whose respective values are ranging from 0 (poor fit) to 1 (perfect fit) [5]. The results for 


\section{Tab. 1: Summary statistics and correlations}

\begin{tabular}{l|l|c|c|c|c|c|c|c|c|c} 
& & $\mathbf{M}$ & SD & $\mathbf{1}$ & $\mathbf{2}$ & $\mathbf{3}$ & $\mathbf{4}$ & $\mathbf{5}$ & $\mathbf{6}$ & $\mathbf{7}$ \\
\hline 1 & Age & 34.4 & 8.14 & --- & & & & & & \\
\hline 2 & Gender & 1.4 & 0.48 & $-0.17^{* *}$ & --- & & & & & \\
\hline 3 & Tenure & 9.3 & 7.94 & $0.83^{* *}$ & -0.06 & -- & & & & \\
\hline 4 & Job satisfaction & 3.7 & 0.80 & $0.18^{* *}$ & $-0.12^{*}$ & $0.14^{*}$ & --- & & & \\
\hline 5 & Turnover intentions & 2.3 & 1.10 & $-0.14^{*}$ & -0.04 & -0.09 & $-0.30^{* *}$ & --- & & \\
\hline 6 & P-O fit & 3.7 & 0.75 & $0.14^{*}$ & -0.11 & $0.12^{*}$ & $0.70^{* *}$ & $-0.29^{* *}$ & --- & \\
\hline 7 & Supportive leadership & 3.5 & 0.81 & 0.01 & 0.01 & 0.01 & $0.41^{* *}$ & $-0.17^{* *}$ & $0.47^{* *}$ & --- \\
\hline
\end{tabular}

Source: own

Note: $\mathrm{N}=310 ;{ }^{*} \mathrm{p}<0.05 ;{ }^{* *} \mathrm{p}<0.0$

4-factor model are much closer to 1, comparing with the others. Also, the RMSEA value for 4-factor model is smaller than .08, which is an acceptable threshold [27]. Finally, smaller AIC values suggest a good fitting, when comparing models [2]. AIC has the lowest value for our hypothesized model. Therefore, CFA results show that our hypothesized 4-factor model fit the data better than any of the three alternative models. Thus, we proceed with our analyses.

Our multiple regression results to test the mediating role of organizational fit in the relationships between supportive leadership, job satisfaction, and turnover intentions; after controlling age, gender, and tenure are provided in Table 3. In steps $1 \mathrm{a}, \mathrm{b}$, and $\mathrm{c}$, the only significant control variable-outcome relationship was between the controls of age and turnover intentions. In step 2a, the results indicate that supportive leadership is positively and significantly related to $\mathrm{P}-\mathrm{O}$ fit $(\beta=0.47$, $p<0.00)$. Therefore, we accept Hypothesis 1, and this finding passes the first step of Baron and Kenny's [4] three-step mediation analysis. We examine steps $2 b$ and $c$ in order to pass the second step of Baron and Kenny's approach. The results show that supportive leadership was positively related to job satisfaction $(\beta=$ $0.41, p<0.00$ ) and negatively related to turnover intentions $(\beta=-0.17, p<0.05)$. These findings pass the second step and allow us to proceed to the final step and test for mediation. In the third and final step (labeled steps $3 b$ and $c$ ), the results indicate that $\mathrm{P}-\mathrm{O}$ fit was significantly and positively related to job satisfaction $(\beta=$ $0.63, p<0.00)$ and negatively related to turnover

\section{Tab. 2: Results of confirmatory factor analyses}

\begin{tabular}{l|c|c|c|c|c|c|c|c}
\multicolumn{1}{c|}{ Model } & $\mathbf{x}^{2}$ & $\mathbf{D f}$ & $\Delta \mathbf{x}^{2}$ & $\Delta$ Df & CFI & TLI & AIC & RMSEA \\
\hline $\begin{array}{l}\text { Hypothesized Model } \\
\text { (4-Factor) }\end{array}$ & 905 & 341 & - & - & 0.91 & 0.89 & 1,035 & 0.07 \\
\hline $\begin{array}{l}\text { 3-Factor Model 1 } \\
\text { (combining PO and JS) }\end{array}$ & 1,242 & 347 & $337^{\star *}$ & 6 & 0.85 & 0.83 & 1,360 & 0.09 \\
\hline $\begin{array}{l}\text { 3-Factor Model 2 } \\
\text { (combining JS and SL) }\end{array}$ & 1,876 & 347 & $971^{\star *}$ & 6 & 0.73 & 0.71 & 1,993 & 0.11 \\
\hline $\begin{array}{l}\text { 3-Factor Model 3 } \\
\text { (combining SL and PO) }\end{array}$ & 2,022 & 347 & $1,117^{\star *}$ & 6 & 0.71 & 0.69 & 2,140 & 0.12 \\
\hline
\end{tabular}

Note: $\mathrm{PO}=$ Person-Organizational fit, JS = Job satisfaction, SL = Supportive Leadership, 
intentions $(\beta=-0.26, p<0.00)$. These findings provide support for Hypotheses $2 a$, and $b$. Moreover, the findings show that although supportive leadership was significantly related to our outcome variables, with $\mathrm{P}-\mathrm{O}$ fit in the equation it no longer indicates a significant relationship with turnover intentions and still shows a significant relationship with job satisfaction. However, the betas for supportive leadership predicting job satisfaction dropped from 0.41 to 0.11 . Therefore, P-O fit fully mediated the relationship between supportive leadership and turnover intentions, while it partially mediates the association between supportive leadership and job satisfaction. In order to provide additional evidence for mediation, we applied Sobel test by using Preacher and Hayes's [34] macros to measure the significance of indirect effects of supportive leadership on each of the two outcome variables via $\mathrm{P}-\mathrm{O}$ fit. Sobel test have been found to have good statistical power, when evaluating mediation [28], [34]. Therefore, we used both Baron \& Kenny's approach [4] and Sobel test [39] together in order to have a more powerful strategy for testing mediation. The results of Sobel test support the significance of indirect effects of supportive leadership on job satisfaction $(z=7.87, p<.00)$ and turnover intentions $(z=-3.97, p<.00)$ via P-O fit. Finally, Hypotheses $3 a$, and $b$ are supported.

\section{Discussion}

The fundamental goal of this study is to test the mediating role of person-organization fit between supportive leadership and two outcomes such as job satisfaction and turnover intentions. Our results provide support for our hypotheses and make contributions to the supportive leadership and person-organization fit literature.

We first analyze the relationship between supportive leadership and $\mathrm{P}-\mathrm{O}$ fit. We find that supportive leadership positively affects $\mathrm{P}-\mathrm{O}$ fit, which is in line with social exchange theory since supportive leader behavior affects the employee behavior and employees look for balance (e.g. the quality of support, and the availability of resources) in their relationship with their employing organization [7]. Also, findings are consistent with the need-supplies perspective, namely, P-O fit occurs when an organization satisfies individuals' needs, desires or preferences [25]. Therefore, supportive leader behavior becomes an instrument to satisfy such kinds of needs, desires and preferences, which will ultimately motivate employees in order to think that they will fit better to organization.

\begin{tabular}{|c|c|c|c|c|c|c|c|c|c|}
\hline \multirow{4}{*}{\multicolumn{2}{|c|}{$\begin{array}{l}\text { Tab. 3: } \\
\text { Dependent }\end{array}$}} & \multicolumn{8}{|c|}{$\begin{array}{l}\text { Regression results to test the mediating role of person-organization fit } \\
n \text { the relationship between supportive leadership, job satisfaction, } \\
\text { ind turnover intentions }\end{array}$} \\
\hline & & \multicolumn{2}{|c|}{ P-O Fit } & \multicolumn{3}{|c|}{ Job Satisfaction } & \multicolumn{3}{|c|}{ Turnover Intentions } \\
\hline & & Step1a & Step2a & Step1b & Step2b & Step3b & Step1c & Step2c & Step3c \\
\hline & & $\beta$ & $\beta$ & $\beta$ & $\beta$ & $\beta$ & $\beta$ & $\beta$ & $\beta$ \\
\hline Control Age & & 0.09 & 0.09 & 0.16 & 0.16 & 0.10 & $-0.21^{\star}$ & $-0.21^{*}$ & -0.19 \\
\hline Gender & & -0.09 & -0.09 & -0.10 & -0.10 & -0.04 & -0.07 & -0.07 & -0.10 \\
\hline Tenure & & 0.03 & 0.02 & 0.00 & -0.01 & -0.02 & 0.07 & 0.08 & 0.08 \\
\hline \multicolumn{10}{|c|}{ Independent variable } \\
\hline Supportive lea & dership & & $0.47^{\star *}$ & & $0.41^{\star *}$ & $0.11^{*}$ & & $-0.17^{\star}$ & -0.04 \\
\hline \multicolumn{10}{|l|}{ Mediator } \\
\hline P-O Fit & & & & & & $0.63^{* \star}$ & & & $-0.26^{* *}$ \\
\hline $\mathrm{R}^{2}$ & & 0.03 & 0.25 & 0.04 & 0.21 & 0.52 & 0.02 & 0.05 & 0.10 \\
\hline Change in $\mathrm{R}^{2}$ & & $0.03^{*}$ & $0.22^{\star \star}$ & $0.04^{*}$ & $0.17^{\star \star}$ & $0.31^{* *}$ & $0.02^{*}$ & $0.03^{*}$ & $0.05^{\star \star}$ \\
\hline
\end{tabular}

Note: $N=310 ;{ }^{*} p<0.05 ;{ }^{* *} p<0.001$ 
We also reveal that person-organization fit predicts the outcomes measured in this research. According to ASA theory, individuals are attracted to organizations, that have values similar to their own (attraction), and organizations select individuals who share their values (selection), and finally individuals who do not fit to organization will leave voluntarily or be asked to leave (attrition) [37], [12]. Taken these together, high $\mathrm{P}-\mathrm{O}$ fit will provide more satisfied employees and employees with high $\mathrm{P}-\mathrm{O}$ fit will show less turnover intentions. These findings are also in line with previous studies [37], [31], [11], [44] [26], which helps to establish generalizability.

Our final and the most interesting finding is the mediating role of $\mathrm{P}-\mathrm{O}$ fit in the relationships between supportive leadership and outcomes. Specifically, P-O fit partially mediates the relationship between supportive leadership and job satisfaction, while it plays a full mediator role for the relationship between supportive leadership and turnover intentions. The extant literature has shown that supportive leadership is to be associated with job satisfaction, as well as turnover intentions. However, our results reveal that person-organization fit is an intermediary mechanism that provides an explanation for how leader support affects workplace outcomes. In other words, leader support promotes P-O fit and P-O fit increases job satisfaction and decreases turnover intentions of employees. When managers provide support and create friendly and psychologically supportive work environments for their subordinates, this will probably help to increase subordinates' self confidence and motivate them for their needs and preferences are satisfied in that organization, which ultimately causes the increase of the employee's perceived value congruence. Thus, their perception of fit to organization will increase, which in turn results with increased level of job satisfaction and decreased level of turnover intentions. This finding is also vital given the important role of employee retention, which plays in organization's success. Further, findings emphasize that P-O fit partially mediates the relationship between supportive leadership and job satisfaction. Therefore, there should be other potential intermediary mechanisms such as perceived control, commitment, locus of control or stress level of employees between these relations. Such mechanisms should be analyzed for future research.
Although this study makes a number of contributions to the extant literature, there are some limitations that should be considered in order to properly interpret the findings. First, our study has cross-sectional nature and this prevents us to test more complicated relationships (e.g. recursive relationships). Therefore, we invite future researchers to analyze our hypotheses in a longitudinal study, which will reveal that how leader support, person-organization fit, and outcome relationships will change over time. Future research with cross sectional and longitudinal data is necessary to confirm and generalize our findings. Another limitation is that our variables measured the perceptions of employees, namely they were measured from a single employee's perspective, which may leads to common source concerns [33]. Some of the procedural remedies recommended by Podsakoff and his colleagues [33] were used to reduce method biases at the response reporting stage. The respondents, for instance were assured that there is no right or wrong answer to each of question and also we informed them about their anonymities will be protected. These procedures will reduce respondent's evaluation apprehension and make them less likely to edit their responses in order to be socially desirable, acquiescent, and consistent with how they think the researcher wants them to respond [33]. Our final limitation is that our respondents in this study came from telecommunication industry, which may have unique characteristics not found in other organizations. Also, this study has taken place in Turkey, which has highly paternalistic and moderately collectivistic cultural characteristics [3]. Thus, there is a need for replication of our study in other samples and cultures for the generalizability of the findings.

As practical implications, our findings provide evidence that leader support affects important outcomes through the intermediary mechanism of person-organization fit. Therefore, organizations can train their managers and provide resources to them in order to increase their supportiveness, which will cause the increase of the value congruence and fit of the employees and this will result with the increase of the employee satisfaction and retention. Some organizations also can be restructured in order to provide individuals more support. Organizations can also attract high-skilled job candidates by creating friendly 
and psychologically supportive working environments, in which the candidates will think that they fit to such organizations better. Further, organizations may select employees with high $\mathrm{P}-\mathrm{O}$ fit during the recruitment and selection process, which will help to reduce the turnover risk. All in all, these efforts will help organizations in order to create competitive advantages through maximizing desirable employee behaviors.

\section{Conclusion}

This study investigates the mediating role of person-organization fit in the supportive leadership-outcome relationships. The results show that person-organization fit is an explanatory variable that mediates the relationships between supportive leadership and the outcomes of job satisfaction and turnover intentions. In particular, higher levels of supportive leadership predicts greater P-O fit, which in turn is a significant predictor of higher levels of job satisfaction and lower levels of turnover intentions. Empirical findings of the present study support the extending literature and makes vital contribution by showing the explanatory mechanism of person-organization fit. Therefore, managers would benefit from establishing and maintaining friendly and psychologically supportive work environments which would allow employees to develop their self confidence, motivation, and relationship with their managers. Thus, their perceived value congruence with the organization will increase and they fit better to the organization, which in turn results with increased level of job satisfaction and decreased level of turnover intentions. Also, when managers look out for the personal welfare and interests of their employees and help them overcoming their problems by acting friendly and considerate, these will motivate employees and increase their performance. Further, supportive leader behavior is an excellent tool to alleviate the stressful situations for employees. Therefore, managers should promote employee support programs that provide organizations a mechanism through which employee behaviors can be favorably affected. Organizations should invest in such kind of support programs. Future studies will extend our findings and test more complex models by using longitudinal data.

\section{References}

[1] AGHO, A.O., PRICE, J.L., MUELLER, C.W. Discriminant Validity of Job Satisfaction, Positive Affectivity and Negative Affectivity. Journal of Occupational and Organizational Psychology. 1992, Vol. 65, Iss. 3, pp. 185196. ISSN 2044-8325. DOI: 10.1111/j.20448325.1992.tb00496.x.

[2] AKAIKE, H. A new look at the statistical model identification. IEEE Transactions on Automatic Control. 1974, Vol. 19, Iss. 6, pp. 716-723. ISSN 0018-9286. DOI: 10.1109/TAC.1974.1100705.

[3] AYCAN, Z. Human resource management in Turkey: Current issues and future challenges. International Journal of Manpower. 2001, Vol. 22, Iss. 3, pp. 252-260. ISSN 0143-7720. DOI: 10.1108/01437720110398347.

[4] BARON, R.M., KENNY, D.A. The moderator-mediator variable distinction in social psychological research: Conceptual, strategic, and statistical considerations. Journal of Personality and Social Psychology. 1986, Vol. 51, Iss. 6, pp. 1173-1182. ISSN 0022-3514. DOI: 10.1037/0022-3514.51.6.1173.

[5] BENTLER, P.M. Comparative fit indexes in structural models. Psychological Bulletin. 1990, Vol. 107, Iss. 2, pp. 238-246. ISSN 0033-2909. DOI: 10.1037/0033-2909.107.2.238.

[6] BENTLER, P.M., BONETT, D.G. Significance tests and goodness of fit in the analysis of covariance structure. Psychological Bulletin. 1980, Vol. 88, Iss. 3, pp. 588-606. ISSN 0033-2909. DOI: 10.1037/0033-2909.88.3.588. [7] BLAU, P.M. Exchange and Power in Social Life. New York: Wiley, 1964.

[8] BLUEDORN, A.C. A unified model of turnover from organizations. Human Relations. 1982, Vol. 35, Iss. 2, pp. 135-153. ISSN 00187267. DOI: $10.1177 / 001872678203500204$.

[9] BRAYFIELD, A.H., ROTHE, H.F. An Index of Job Satisfaction. Journal of Applied Psychology. 1951, Vol. 35, Iss. 5, pp. 307-311. ISSN 0021-9010. DOI: 10.1037/h0055617.

[10] BRISLIN, R.W. Translation and content analysis of oral and written materials. In: TRIANDIS, H.C., BERRY, J.W. (Eds.). Handbook of cross-cultural psychology: Methodology. Vol. 2. Boston: Allyn and Bacon, 1980. ISBN 978-0205064984.

[11] CHATMAN, J.A. Matching people and organizations: Selection and socialization in public accounting firms. Administrative Science Quarterly. 1991, Vol. 36, Iss. 3, pp. 459-484. ISSN 0001-8392. DOI: 10.2307/2393204. 
[12] COOMAN, R.D., et al. Person-organization fit: Testing socialization and attractionselection-attrition hypotheses. Journal of Vocational Behavior. 2009, Vol. 74, Iss. 1, pp. 102-107. ISSN 0001-8791. DOI: 10.1016/j. jvb.2008.10.010.

[13] DOWNEY, H.K., HELLRIEGEL, D., SLOCUM, J.W. Congruence between individual needs, organizational climate, job satisfaction and performance. Academy of Management Journal. 1975, Vol. 18, Iss. 1, pp. 149-155. ISSN 0001-4273. DOI: 10.2307/255634.

[14] EISENBERGER, R., et al. Perceived supervisor support: Contributions to perceived organizational support and employee retention. Journal of Applied Psychology. 2002, Vol. 87, Iss. 3, pp. 565-573. ISSN 0021-9010. DOI: 10.1037/0021-9010.87.3.565.

[15] EMMONS, R.A., DIENER, E., LARSEN, R.J. Choice and avoidance of everyday situations and affect congruence: Two models of reciprocal interactionism. Journal of Personality and Social Psychology. 1986, Vol. 51, Iss. 4, pp. 815-826. ISSN 0022-3514. DOI: 10.1037/0022-3514.51.4.815.

[16] ENZ, C.A. Power and Shared Values in the Corporate Culture. Ann Arbor, MI: UMI Research Press, 1986. ISBN 978-0835717380. [17] GERSTNER, C.R., DAY, D.V. Metaanalytic review of leader-member exchange theory: Correlates and construct ideas. Journal of Applied Psychology. 1997, Vol. 82, Iss. 6, pp. 827-844. ISSN 0021-9010. DOI: 10.1037/00219010.82.6.827.

[18] GRAEN, G., CASHMAN, J. A role-making model of leadership in formal organizations: a developmental approach. In: HUNT, J.G., LARSON, L.L. (Eds.). Leadership Frontier. Kent, OH: Kent State University Press, 1975. pp. 143-165. ISBN 978-0873381819.

[19] HOUSE, R.J. A path-goal theory of leader effectiveness. Administrative Science Quarterly. 1971, Vol. 16, Iss. 3, pp. 321-339. ISSN 0001-8392. DOI: 10.2307/2391905.

[20] HOUSE, R.J., MITCHELL, T.R. Path-goal theory of leadership. Journal of Contemporary Business. 1974, Vol. 3, Iss. Autumn, pp. 81-97. ISSN 0194-0430.

[21] HOUSE, R.J., DESSLER, G. The pathgoal theory of leadership: Some post hoc and a priori tests. In: HUNT, J.G., LARSON, L.L. (Eds.). Contingency approaches to leadership. Carbondale: Southern Illinois University Press, 1974. ISBN 978-0809306893.
[22] HOUSE, R.J. Path-goal theory of leadership: Lessons, legacy, and a reformulated theory. Leadership Quarterly. 1996, Vol. 7, Iss. 3, pp. 323-352. ISSN 1048-9843. DOI: 10.1016/ S1048-9843(96)90024-7.

[23] JUDGE, T.A., PICCOLO, R.F., ILIES, R. The forgotten ones? The validity of consideration and initiating structure in leadership research. Journal of Applied Psychology. 2004, Vol. 89, Iss. 1 , pp. 36-51. ISSN 0021-9010. DOI: 10.1037/0021-9010.89.1.36.

[24] JUNG, H.S., NAMKUNG, Y., YOON, H.H. The effects of employees' business ethical value on person-organization fit and turnover intent in the foodservice industry. International Journal of Hospitality Management. 2010, Vol. 29 , Iss. 3, pp. 538-546. ISSN 0278-4319. DOI: 10.1016/j.ijhm.2009.08.005.

[25] KRISTOF, A.L. Person-organization fit: An integrative review of its conceptualizations, measurement, and implications. Personnel Psychology. 1996, Vol. 49, Iss. 1, pp. 1-49. ISSN 1744-6570. DOI: 10.1111/j.1744-6570.1996. tb01790.x.

[26] KRISTOF-BROWN, A.L., ZIMMERMAN, R.D., JOHNSON, E.C. Consequence of individual's fit at work: A meta-analysis of person-job, person-organization, persongroup and person-supervisor fit. Personnel Psychology. 2005, Vol. 58, Iss. 2, pp. 281342. ISSN 1744-6570. DOI: 10.1111/j.17446570.2005.00672.x.

[27] MACCALLUM, R.C., BROWNE, M.W., SUGAWARA, H.M. Power analysis and determination of sample size for covariance structure modeling. Psychological Methods. 1996, Vol. 1, Iss. 2, pp. 130-149. ISSN 1082989X. DOI: 10.1037/1082-989X.1.2.130.

[28] MACKINNON, D.P., et al. A comparison of methods to test mediation and other intervening variable effects. Psychological Methods. 2002, Vol. 7, Iss. 1, pp. 83-104. ISSN 1082-989X. DOI: 10.1037/1082-989X.7.1.83.

[29] MEYER, J.P., ALLEN, N.J. Testing the "side-bet theory" of organizational commitment: Some methodological considerations. Journal of Applied Psychology. 1984, Vol. 69, Iss. 3, pp. 372-378. ISSN 0021-9010. DOI: 10.1037/00219010.69.3.372.

[30] MITCHELL, T.R., et al. Why people stay: using job embeddedness to predict voluntary turnover. Academy of Management Journal. 2001, Vol. 44, Iss. 6, pp. 1102-1121. ISSN 0001-4273. DOI: 10.2307/3069391. 
[31] O'REILLY, C.A., CHATMAN, J., CALDWELL, D.F. People and organizational culture: A profile comparison approach to assessing person-organization fit. Academy of Management Journal. 1991, Vol. 34, Iss. 3, pp. 487-516. ISSN 0001-4273. DOI: 10.2307/256404.

[32] PERVIN, L.A., RUBIN, D.B. Student dissatisfaction with college and the college dropout: A transactional approach. Journal of Social Psychology. 1967, Vol. 72, Iss. 2, pp. 285-295. ISSN 0022-4545. DOI: 10.1080/00224545.1967.9922326.

[33] PODSAKOFF, P.M., MACKENZIE, S.B., PODSAKOFF, N.P., LEE, J.Y. Common method biases in behavioral research: A critical review of the literature and recommended remedies. Journal of Applied Psychology. 2003, Vol. 88, Iss. 5, pp. 879-903. ISSN 0021-9010. DOI: 10.1037/0021-9010.88.5.879.

[34] PREACHER, J.K., HAYES, A.F. SPSS and SAS procedures for estimating indirect effects in simple mediation models. Behavior Research Methods, Instruments, \& Computers. 2004, Vol. 36, Iss. 4, pp. 717-731. ISSN 0743-3808. DOI: 10.3758/BF03206553.

[35] RAFFERTY, A.E., GRIFFIN, M.A. Refining individualized consideration: Distinguishing developmental leadership and supportive leadership. Journal of Occupational and Organizational Psychology. 2006, Vol. 79, Iss. 1, pp. 37-61. ISSN 2044-8325. DOI: 10.1348/096317905X36731.

[36] SAKS,A.M., UGGERSLEV, K.L., FASSINA, N.E. Socialization tactics and newcomer adjustment: A meta-analytic review and test of a model. Journal of Vocational Behavior. 2007, Vol. 70, Iss. 3, pp. 413-446. ISSN 0001-8791. DOI: 10.1016/j.jvb.2006.12.004.

[37] SCHNEIDER, B. The people make the place. Personnel Psychology. 1987, Vol. 40, Iss. 3, pp. 437-453. ISSN 1744-6570. DOI: 10.1111/j.1744-6570.1987.tb00609.x.

[38] SCHNEIDER, B., GOLDSTEIN, H.W., SMITH, D.B. The ASA Framework: An update. Personnel Psychology. 1995, Vol. 48, Iss. 4, pp. 747-773. ISSN 1744-6570. DOI: 10.1111/ j.1744-6570.1995.tb01780.x.

[39] SOBEL, M.E. Asymptotic intervals for indirect effects in structural equations models. In: LEINHART, S. (Ed.). Sociological methodology. San Francisco: Jossey-Bass, 1982. ISBN 978-0875895161.
[40] SOUSA-POZA, A., HENNEBERGER, F. An Empirical Analysis of Working-Hours Constraints in 21 Countries. Review of Social Economy. 2002, Vol. 60, Iss. 2, pp. 209-242. ISSN 00346764. DOI: 10.1080/00346760210146235.

[41] SPECTOR, P.E. Job satisfaction: Application, assessment, causes, and consequences. Thousand Oaks, CA: Sage Publications, 1997. ISBN 978-0761989233.

[42] TEPECI, M., BARTLETT, A.L.B. The Hospitality industry culture profile: A measure of individual values, organizational culture, and person-organization fit as predictors of job satisfaction and behavioral intentions. International Journal of Hospitality Management. 2002, Vol. 21, Iss. 2, pp. 151-170. ISSN 02784319. DOI: 10.1016/S0278-4319(01)00035-4.

[43] TUTEN, T.L., NEIDERMEYER, P.E. Performance, satisfaction and turnover in call center: The effects of stress and optimism. Journal of Business Research. 2004, Vol. 57, Iss. 1, pp. 26-34. ISSN 0148-2963. DOI: 10.1016/S0148-2963(02)00281-3.

[44] VERQUER, M.L., BEEHR, T.A., WAGNER, S.H. A meta-analysis of relations between person-organization fit and work attitudes. Journal of Vocational Behavior. 2003, Vol. 63, Iss. 3, pp. 473-489. ISSN 0001-8791. DOI: 10.1016/S0001-8791(02)00036-2.

[45] WATERMAN, R.H., WATERMAN, J.A., COLLARD, B.A. Toward a career-resilient workforce. Harvard Business Review. 1994, Iss. July-August, pp. 87-95. ISSN 0017-8012.

Prof. Alptekin Sökmen, Ph.D. Gazi University

Faculty of Economics and Administrative Sciences

Business Administration Department asokmen@gazi.edu.tr

M. Gökhan Bitmiş, Ph.D.

Gazi University

Faculty of Economics and Administrative Sciences

Business Administration Department mgbitmis@gazi.edu.tr

Prof. M. Mithat Üner, Ph.D. Gazi University

Faculty of Economics and Administrative Sciences

Business Administration Department mithatuner@gazi.edu.tr 


\title{
Abstract
}

\section{THE MEDIATING ROLE OF PERSON-ORGANIZATION FIT IN THE SUPPORTIVE LEADERSHIP-OUTCOME RELATIONSHIPS}

\author{
Alptekin Sökmen, M. Gökhan Bitmiş, M. Mithat Üner
}

This study examines whether person-organization fit ( $P-O$ fit) would mediate the relationships of supportive leadership with the outcome variables of turnover intentions and job satisfaction. We collected data from a survey of 310 telecommunication employees in Turkey. Our results show that $\mathrm{P}-\mathrm{O}$ fit fully mediates the relationship between supportive leadership and turnover intentions, while $P$-O fit partially mediates the relationship between supportive leadership and job satisfaction. Therefore, person-organization fit is an intermediary mechanism that explains the supportive leadership-outcome relationships. In other words, supportive leadership behavior influences job satisfaction and turnover intentions through the person-organization fit. Specifically, higher levels of supportive leadership behavior predicts greater $\mathrm{P}-\mathrm{O}$ fit, which in turn is a significant predictor of higher levels of job satisfaction and lower levels of turnover intentions. We evaluated both Baron \& Kenny's approach and Sobel test together in order to achieve more powerful strategy when testing mediation (P-O fit). Both approaches provide evidence for the mediation effect of personorganization fit in this study. Age, gender, and tenure were controlled in order to eliminate spurious relationships. Further, we also examined a series of confirmatory factor analyses, which includes our hypothesized four factor model and three alternative models in order to provide additional evidence for the discriminant validity. Results reveal that hypothesized four factor model fit the data better than any of the three alternative models. The findings of the study suggest important implications for management theory and practice. For instance, when managers provide support and create friendly and psychologically supportive work environments, this promotes employees' perceived value congruence with their organization and employees probably perceive that they will fit better to such organization, which in turn results with increased level of job satisfaction and decreased level of turnover intentions.

Key Words: Supportive leadership, person-organization fit, job satisfaction, turnover intentions, mediation.

JEL Classification: M12, L29.

DOI: 10.15240/tul/001/2015-3-006 